\title{
UMA ANÁLISE NA COOPERATIVA DE PRODUÇÃO DOS AGRICULTORES FAMILIARES DO TERRITÓRIO DO BICO DO PAPAGAIO
}

\author{
Erica Ribeiro de Sousa Simonetti ${ }^{1 *}$, Aline Correia Silva Oliveira ${ }^{2}$ \\ ${ }^{1}$ Economista, Me. Gestão e Desenvolvimento Regional-UNITAU-SP, Professora no IFTO- Campus Araguatins- TO \\ ${ }^{2}$ Servidora do IFTO- Campus Araguatins- TO, Esp. Em Gestão Ambiental e Docência no ensino superior \\ Autor para correspondência: Erica Ribeiro de Sousa Simonetti, erica.simonetti@ifto.edu.br
}

RESUMO: As cooperativas são sociedades de pessoas, com forma e natureza jurídica próprias, de natureza civil, não sujeitas a falência, constituídas para prestar serviços aos associados além de promover um desenvolvimento regional, promove através de programas de educação voltados aos seus cooperados e comunidades. As estratégias utilizadas ocasionam um aumento da competitividade à medida que obtém maior poder de negociação nas transações e melhoria de preços aos produtores. Ademais, possuem como fundamento o princípio de oferecer qualidade de vida aos seus cooperados, através de produtos e serviços, e principalmente trabalham o desenvolvimento sustentável de suas comunidades, por meio de políticas consentidas pelos seus membros, assumindo com isso o compromisso com a responsabilidade social, compromisso com a responsabilidade social Com relação a agricultura familiar, é cada vez mais crescente a criação de cooperativas para expandir seu mercado de comercialização garantindo, assim, renda para um número maior de famílias. Considerando a relevância das Cooperativas para os produtores rurais, no lançamento do Plano Safra 2015/2016, foi assinada a portaria 204 que criou o Programa Nacional do Fortalecimento do Cooperativismo e Associativismo Solidário da Agricultura Familiar e Reforma Agrária (COOPERAF)).O presente estudo tem por objetivo caracterizar a Cooperativa COOPERBICO fundada em setembro de 2016 no município de Araguatins no estado do Tocantins. A pesquisa e do tipo descritiva exploratória bibliográfica e de campo utilizou-se como instrumento de coleta de informações um questionário semiestruturado. Conclui-se que a Cooperativa fundada em Araguatins é vista como uma alternativa aos pequenos produtores rurais , no que tange a capacitação técnica, incremento da tecnologia e expansão da produção, com venda em comum da produção e da prestação de serviços dos seus associados compreendendo.

PALAVRAS-CHAVE: Cooperativas, produtores familiares, produtividade

\section{AN ANALYSIS IN THE PRODUCTION COOPERATIVE OF FAMILY FARMERS IN THE TERRITORY OF THE PARROT}

\begin{abstract}
The cooperatives are societies of persons, with their own legal form and nature, of a civil nature, not subject to bankruptcy, constituted to provide services to the members besides promoting a regional development, promotes through education programs directed to its members and communities. The strategies used increase competitiveness as it obtains greater bargaining power in transactions and improves prices to producers. In addition, they are based on the principle of offering quality of life to their members through products and services, and mainly work for the sustainable development of their communities, through policies agreed by its members, thereby assuming the commitment to social responsibility , A commitment to social responsibility With regard to family farming, the creation of cooperatives to expand their marketing market is increasing, thus guaranteeing income for a larger number of families. Considering the relevance of Cooperatives to rural producers, at the launching of the 2015/2016 Harvest Plan, a decree 204 was signed that created the National Program for Strengthening Cooperatives and Solidarity Association of Family Agriculture and Agrarian Reform (Cooperaf). By objective to characterize Cooperativa Cooperbico founded in September of 2016 in the municipality of Araguatins in the state of Tocantins. The research was descriptive exploratory bibliographical and field, a semi-structured questionnaire was used as a tool for collecting information. It is concluded that Cooperbico is seen as an alternative to small rural producers, regarding technical training, Technology and production expansion, with the common sale of the production and service of its associates, comprising.
\end{abstract}

KEYWORDS: Cooperatives, Family producers, Productivy 


\section{INTRODUÇÃO}

Desde tempos remotos, é inegável que o homem pratica o sistema de cooperação, nota-se na união na caça, pesca e cultivo da terra. No Brasil, com o crescimento do sistema cooperativista é possível considerá-lo como uma ferramenta de suma importância para o aumento da economia do país, 0 relatório de atividades da Organização das Cooperativas Brasileiras (OCB, 2013, p. 19), revela que o sistema cooperativista tem contribuído de forma significativa para redução dos índices de desemprego.

De acordo com a Lei $n^{0} 5.764 / 71$, no seu artigo $4^{0}$, "As cooperativas são sociedades de pessoas, com forma e natureza jurídica próprias, de natureza civil, não sujeitas a falência, constituídas para prestar serviços aos associados, distinguindo-se das demais sociedades. Destarte, para a Organização das Cooperativas Brasileiras (2017) e uma associação autônoma de pessoas que se unem voluntariamente, para satisfazer aspirações e necessidades econômicas, sociais e culturais comuns, por meio de uma empresa de propriedade coletiva e democraticamente gerida.

Baseiam-se em determinados valores conforme Pacheco et al. (2008) os valores que permeiam o cooperativismo no mundo são de autoajuda, solidariedade, igualdade, equidade, democracia e auto responsabilidade. São padrões éticos como base de conduta, os quais que balizam os princípios cooperativistas e estes que devem orientar as decisões das organizações.

Conforme OCB (2017) são 13 ramos de Cooperativas: Agropecuário: reúne produtores rurais; Consumo, Habitacional: (direcionada aos que precisam de moradia) Produção; Crédito Educacional, entre outros, este trabalho se delimita nas cooperativas de produtores rurais.

O cooperativismo tem influenciado de forma crescente no desenvolvimento social e econômico, tanto de pessoas, organizações e territórios. Verifica-se que o fortalecimento das cooperativas, e sua crescente participação na organização econômica, social e ambiental na região, estará alavancando os processos de desenvolvimento regional e por consequência ira contribuir na melhoria das condições de vida dos cooperativados e de toda a sociedade.

As cooperativas além de promover um desenvolvimento regional promovem através de programas de educação voltados aos seus cooperados e comunidades. Não obstante as estratégias utilizadas ocasionam um aumento da competitividade à medida que obtém maior poder de negociação nas transações e melhoria de preços aos produtores. Ademais, possuem como fundamento o princípio de oferecer qualidade de vida aos seus cooperados, através de produtos e serviços, e principalmente trabalham o desenvolvimento sustentável de suas comunidades, por meio de políticas consentidas pelos seus membros, assumindo com isso o compromisso com a responsabilidade social.

Com relação à agricultura familiar, é cada vez mais crescente a criação de cooperativas para expandir seu mercado de comercialização garantindo, assim, renda para um número maior de famílias.

O Estado do Tocantins está localizado na parte oeste da região Norte do Brasil, com extensão de $277.720,569 \mathrm{~km}^{2}$, correspondendo a $6,79 \%$ da região Norte e a $2,86 \%$ do território Nacional. Sua capital, Palmas situa-se entre as coordenadas $10^{\circ} 12^{\prime} 46^{\prime \prime}$ de Latitude Sul e 48 $21^{\circ} 37^{\prime \prime}$ de Longitude Oeste, com 230 $\mathrm{m}$ de altitude. Sua vegetação caracteriza-se de Cerrado ( $87 \%$ de seu território) com florestas de transição (12\%).

O Estado limita-se ao Norte com os Estados do Maranhão e Pará, ao Sul com o Estado do Goiás, a Oeste com o Pará e Mato Grosso e a Leste com os Estados do Maranhão, Piauí e Bahia (Portal Tocantins, 2015). Apresenta uma população estimada em 1.515 .126 habitantes com densidade demográfica de 4,98 habitantes/ km², distribuída por 139 municípios (IBGE, 2015).

A microrregião do Bico do Papagaio é uma das microrregiões do estado brasileiro do Tocantins pertencente à mesorregião Ocidental do Tocantins. Tem em sua composição 28 municípios.

Há 14 tipos de setores produtivos de Arranjos Produtivos Locais no Estado do Tocantins: Agricultura (8); Apicultura (2); Artesanato (1); Cerâmica (1) Confecções (1); Economia Criativa (1); Fabricação de móveis (1); Fruticultura (1); Gemas e Jóias (1); Laticínios (1); Ovinocaprinocultura (1) Pecuária (1) Pesca, aquicultura e serviços relacionados (1); Turismo (1) (GTA, 2015).

Aagricultura familiar no Tocantins possui 42.899 unidades produtivas, Sendo, em 2004, responsável por $30,7 \%$ do PIB do setor, com apenas $9,89 \%$ do financiamento direcionado ao setor agrícola do estado em 2003 (BACEN, 2010). 
Considerando a relevância das Cooperativas para os produtores rurais No dia 22 de junho, no lançamento do Plano Safra 2015/2016, foi assinada a portaria 204 que criou o Programa Nacional do Fortalecimento do Cooperativismo e Associativismo Solidário da Agricultura Familiar e Reforma Agrária (COOPERAF). Ele traz um conjunto de ações e diretrizes de estratégias de apoio ao cooperativismo e associativismo (BRASIL, 2017)

0 referente trabalho tem por objetivos caracterizar a Cooperativa COOPERBICO fundada em setembro de 2016 no município de Araguatins no estado do Tocantins.

\section{MATERIAL E MÉTODOS}

Trata-se de uma pesquisa bibliográfica, descritiva exploratória e de campo onde se buscou caracterizar a COOPERBICO, Cooperativa localizada no município de Araguatins - TO, cujo objetivo geral foi identificar, descrever e compreender a realidade e prospecção futura da Cooperativa . 0 instrumento de coleta de dados foi análise documental, e entrevista esta que foi realizada com o presidente atual da Cooperativa Senhor Jose Conceição de Oliveira (Jose Conceição de Oliveira (JOSEDIMAR) através de questionário semiestruturado com um roteiro de perguntas e continha perguntas como: - De onde surgiu a ideia de se montar uma cooperativa? quais as principais dificuldades encontradas para instalação da Cooperativa? Qual a perspectiva futura? Os benefícios para o municípios e cooperados?

\section{RESULTADOS E DISCUSSÃO}

O levantamento feito através de entrevistas indicou que a COOPERBICO foi criada em data de 16 de setembro de 2016, com Sede no município de Araguatins- TO, Área de ação para efeito de admissão de cooperados, circunscrita aos municípios do Território da Cidadania do Bico do Papagaio os objetivos sociais tem base na colaboração recíproca a que se obrigam os seus associados, promover sem finalidade de lucro: I - O estímulo, o desenvolvimento progressivo e a defesa de suas atividades sociais e econômicas, de natureza comum; II - A venda em comum da produção e da prestação de serviços dos seus associados compreendendo: a agricultura tradicional e orgânica, apicultura, piscicultura, agroindústrias, laticínios, avicultura, suinocultura e o extrativismo de palmitos de palmeiras nativas e exóticas, nos mercados locais, nacionais e internacionais. III - A preparação de novas áreas para o desenvolvimento e ampliação das atividades de seus associados.

São 43 pequenos agricultores familiares, participantes ativos da organização sindical e das discussões sobre o momento atual da agricultura familiar, criaram a Cooperativa dos agricultores familiares do território do Bico do Papagaio elegeu a diretoria que fiou encarregada da implantação desse órgão, na Figura 1, ocorreu o momento solene com os cooperados fundadores, e representantes do Sindicato dos trabalhadores rurais de Araguatins, RURALTINS, INCRA, IFTO, UNITINS, SEBRAE e Instituições bancarias.

Figura 1: Sócios fundadores da COOPERBICO

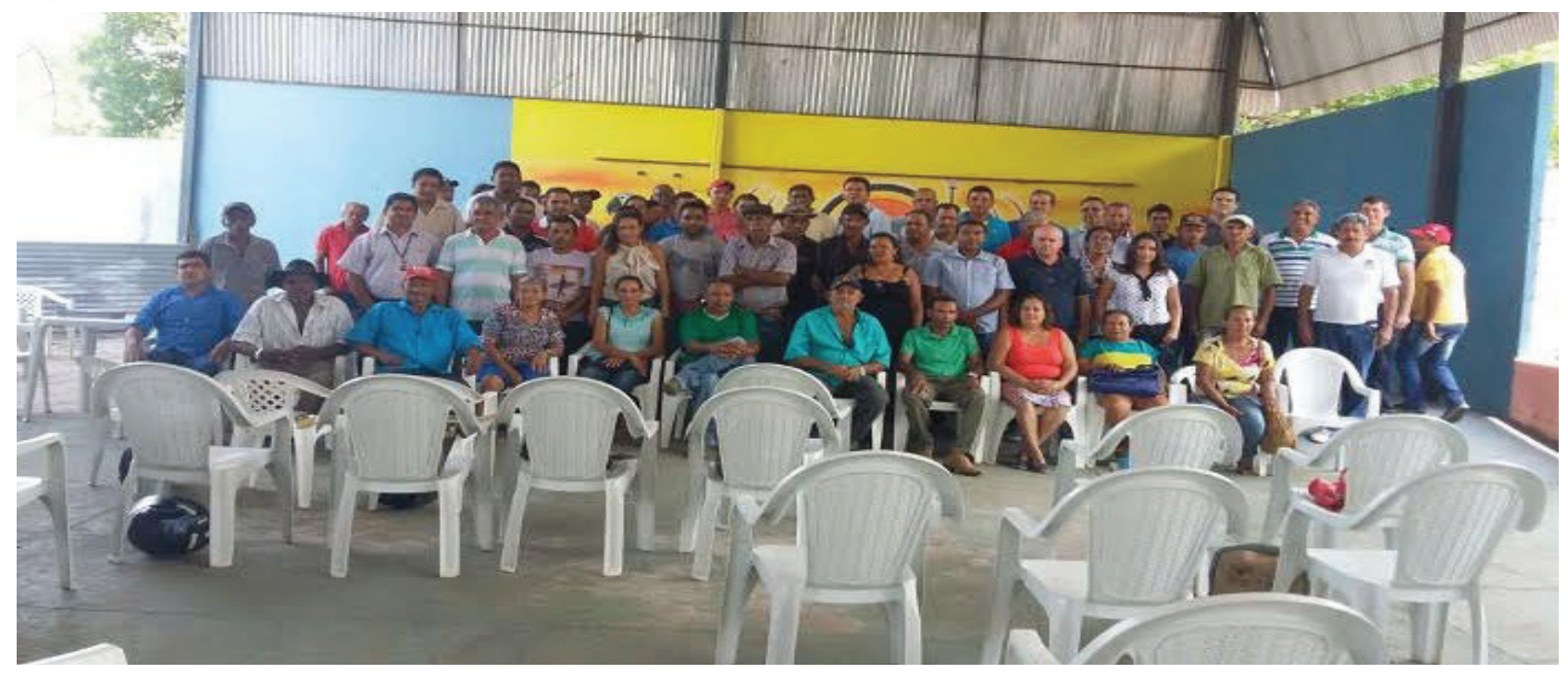

Fonte: Folha do Bico(2016) (www.folhadobico.com.br) 
Esta cooperativa foi criada a partir da necessidade de criar um órgão que representasse a agricultura familiar na região do Bico do Papagaio, junto aos órgãos públicos, para facilitar a aquisição de insumos, agilizar obtenção dos selos de inspeção municipal, Estadual e Federal, comercialização de produtos hortifrutigranjeiros de forma coletiva e ajuda na busca de recursos junto às instituições bancárias. A ideia de criação da cooperativa é de mais de 20 anos, sempre discutido nos conselhos municipais a necessidade, que os agricultores têm de escoar a produção. 0 presidente atual, foi em busca de informações através de visitas em outros lugares, como forma de verificar alguns modelos, foram visitadas cooperativas em Goiás- Luziania, Pará- Ibaitatuba,

Verificou-se que a Cooperativa ainda não tem patrimônio e é administrada por um Conselho de Administração composto de 1 Diretor Presidente, 1 Diretor Administrativo Financeiro, 1 Diretor Secretario e 2 (dois) Conselheiros Vogais, todos cooperados, eleitos democraticamente com mandato de 1(um) a 4 (quatro) anos sendo obrigatória a renovação de no mínimo, 1/3 (um terço) dos seus membros, será registrada e filiada à OCB/TO - Sindicato e Organização das Cooperativas Brasileiras no Estado do Tocantins e para ser um cooperado, é necessário possuir uma terra que seja para sua subsistência, não pode ser um empresário rural

De acordo com o Presidente atual da Cooperativa, para cooperativa se formar e caminhar com as próprias pernas é preciso no mínimo uns 15 anos, para os próximos 12 meses estamos visando estar na nossa própria sede, uma produção mais organizada e de qualidade, fazer com cooperado perceba a importância e da cooperativa e que ele tenha uma produção mais estimulada para entrar no mercado, conseguir a regularização do SIM (Selo de Inspeção municipal), para conseguir efetivar as vendas sic.

Desta forma, conclui-se que o Cooperativismo tem influenciado de forma crescenteno desenvolvimento social e econômico, tanto de pessoas, organizações e territórios, e é cada vez mais crescente a criação de cooperativas na agricultura familiar com 0 intuito de expandir seu mercado de comercialização garantindo, assim, renda para um número maior de famílias.
Verificou-se que a COOPERBICO, tem como escopo inicial de oferecer qualidade de vida aos seus cooperados, através de produtos e serviços, e principalmente trabalham 0 desenvolvimento sustentável de suas comunidades, o que e relevante para seus cooperados e para o município, as parcerias estão se formando, instituição pública e privadas com 0 intuito de fortalecer a produção dos agricultores familiares terem novos acessos de mercado, a Cooperativa e uma estratégia para os agricultores familiares do extremo norte do Tocantins, para a manutenção da renda e melhoria na qualidade de vida.

\section{AGRADECIMENTOS}

Primeiramente a Deus, autor da vida e a família que nosso porto seguro. A COOPERBICO representado pelo Senhor Jose Conceição de Oliveira (JOSEDIMAR) que abriu portas para a realização deste trabalho

\section{REFERÊNCIAS BIBLIOGRÁFICAS}

OCB - Organização das Cooperativas Brasileiras. O Portal do Cooperativismo Brasileiro. Estrutura do Sistema OCB. Disponível em http //www. cooperativismodecredito.coop.br

Ministério Agrícola e Pecuário. Disponível em http:// www.mda.gov.br/sitemda/noticias/cooperativismo-naagricultura-familiar

BACEN. Anuário estatístico do crédito rural. 2010. Disponivel em: <http://www.bcb.gov.br/?RELRURAL>. Acesso em 19 de fevereiro, 2016.

PACHECO, A.S.V.; RISSI, M.; ROCZANSKI, C.R.M.; KLAES, L.S.; COSTA, A.M. Sistematização da avaliação dos programas de educação cooperativa. 